\title{
Biodegradable macromolecule based topical gels containing natural oils in the management of burn wounds
}

\author{
AB Thomas*, AS Kadam, RM Jiwane, RK Nanda and LP Kothapalli \\ Department of Pharmaceutical Chemistry, Dr. D. Y. Patil Institute of Pharmaceutical Sciences and Research, Pimpri, Pune, MS, India
}

\begin{abstract}
Previous studies have demonstrated the role of fatty acids in modulation of various functions in the wound healing process. However, there are very few reports indicating effective utilization of natural oils rich in polyunsaturated fatty acids (PUFA) for treatment of burn wounds. Accordingly, it was thought appropriate to investigate the potential of black cumin, chicken skin and flax seed oils incorporated in topical gel formulations employing biodegradable and bacteriostatic macromolecules like chitosan and carbopol-934. Topical gels/hydrogel systems (F1-F3) containing these selected natural oils were formulated. The prepared formulations were evaluated for their physicochemical characteristics and in vivo testing in rat burn wound healing model. The formulations (F1-F3) exhibited quick film forming ability, adequate mechanical and swelling properties, and efficient water loss capability and may prove to be beneficial in treatment of exudating wounds. In the in vivo burn wound model, significant wound contraction (F1: 69.74 \%, F2: 73.72\%, F3: 70.88\%) with faster reepithilisation comparable to standard silver sufadiazine $0.5 \%$ treated group $(61.3 \%)$ were observed. Histopathological examinations exhibited intense disposition of collagen fibres with active fibroblasts indicating their potential in accelerating the wound healing process. GC-MS analysis of oils confirmed the presence of PUFA like oleic, linoleic, linolenic and ricinoleic acid that are beneficial in wound healing and skin tissue regeneration. Our studies demonstrate that gel formulations prepared incorporating natural oils like black cumin, chicken skin and flax seed oil exhibit significant wound healing properties and may prove beneficial in burn wound management.
\end{abstract}

\section{Introduction}

Topical preparations like gels and hydrogels are among the most frequently used dressing materials in the treatment of wounds and burns. These systems are capable of maintaining moisture at the site of application, allow oxygen penetration and are capable of absorbing water from wound mass. Hydrogels offers several advantages in wound and burn treatment including high bioadhesion to the surface of the skin leading to increased contact with the wound, facilitate greater moisture and water vapor permeability, improved patient compliance with ease of application [1]. Chitosan is a cationic polymer obtained by deacetylation of chitin, and is composed of 2 -amino-2-deoxy- $\beta$ $\mathrm{D}$-glucopyranose residues. Chitosan, in the last decade has received tremendous attention in biomedical and pharmaceutical applications. Their utility in wound healing, hemostasis, immune enhancement with anti-microbial properties, makes it an excellent polymer for use in wound healing and skin tissue regeneration. The cationic dressing and blood clot formation rely on its cationic nature, which allow it to interact with negatively charged biomolecules such as proteins, anionic polysaccharides and nucleic acids, which are located in the skin. Several studies involving fabrication of gels, hydrogels, nanocomposite fibers and scaffolds designed employing chitosan and its oligomers are reported [2]. Aziz M. A. et al. has reported the preparation of chitosan dextran-based hydrogel with antimicrobial efficacy against various bacterial and fungal strains [3]. In a study carried out by Hurler J. et al., bioadhesive properties of chitosan were evaluated and compared with synthetic polymers. Chitosan based formulations exhibited greater bioadhesiveness, confirming its potential in advanced wound healing [4]. In another study, chitosan based hydrogels were prepared by physical and chemical reticulation. The formulated hydrogels were tested for cell viability and apoptosis and were found to be cytocompatible. Chondrocyte were found to be alive but not proliferative indicating their application for cartilage regenerative processes [5]. Dai T. et al. has reported in an extensive review the use of chitosan preparations for treatment of wounds and burns, both by virtue of its intrinsic antimicrobial properties and its ability to deliver extrinsic antimicrobial agents to wounds and burns [6].

Carbopol 934P, a high molecular weight polymer of acrylic is employed in gels, suspensions and emulsions, as a thickening agent. Recently, relevant amount of work has been reported on mucoadhesive properties of carbopol, establishing it as a useful adjuvant for bioadhesive drug delivery system due to its capacity to prolong residence time in organ and increase contact time with absorbing mucosa, resulting in enhancement of drug absorption. As it is a mucoadhesive, biodegradable and environmentally responsive polymer, it is considered as a smart gel $[7,8]$.

Burns cause changes in vascular permeability, aggregation of platelets, extravasation of plasma proteins and increased fibrinolysis [9]. Ruthig D. J. et al. and Pereira L. M. et al. has reported that polyunsaturated fatty acids like oleic and linoleic acids possess significant burn wound healing property [10]. Several studies have been carried out that demonstrate the role of fatty acids in modulation of various functions in the wound healing process, such as differentiation of fibroblasts into myofibroblasts, fibroblasts proliferation, endothelialleukocyte adhesion, keratinocytes differentiation and development of

Correspondence to: Dr. A. B. Thomas, Associate Professor and HOD, Pad. Dr D. Y. Patil Institute of Pharmaceutical Sciences and Research, Pimpri, Pune 411018 (MS), India, Tel: +91-9881236220; E-mail: dypharmachem@yahoo.co.in

Key words: biodegradable macromolecules, burn wounds, natural oils, PUFA, GC-MS

Received: March 02, 2017; Accepted: May 20, 2017; Published: May 24, 2017 
the cutaneous appendages [11]. A recent study carried out by Vincent E. J. et al. has reported that oleic acid is a non-toxic elastase inhibitor and can be effective in the selective lowering of cationic serine protease activity. This may prove to be beneficial in topical application for chronic inflammatory pathogenesis [12]. Oleic and linoleic acids are also reported to possess anti-inflammatory properties. In an open wound excision model in mice, topical treatment with linolenic acid (omega-3), linoleic acid (omega-6), or oleic acid (omega-9) for 20 days demonstrated that wounds treated with oleic acid closed much quicker than ones treated with linoleic acid. Another study indicated that oleic acid down regulated cyclooxygenase 2 (COX-2) and induced collagen type III expression accelerating early wound closure acid [13]. Oleic acid also proved beneficial on early wound epithelialization, but may inhibit later collagen deposition, possibly minimizing scar formation. These studies substantiate the fact that poly unsaturated fatty acids (PUFA) play a significant role in the wound healing process. Plants and animal source derived fats rich in PUFA's have been used to treat burn injuries [14-16]. Based on these findings, it was thought appropriate to select oils rich in PUFA and evaluates their potential in wound healing and skin tissue regeneration.

Black cumin seed oil (BCO) obtained from Nigella sativa Linn. (Ranunculaceae) contains fixed oils like linoleic acid, oleic acid and palmitic acid [17-19]. The USDA Foreign Agricultural Services, Global Agricultural Information Network (GAIN) report IN5124 stated that in the year 2016, the broiler production in India will rise to 4.2 million tons, up by approximately eight percent as compared to the previous year [20]. The poultry industry generates a high amount of residues, including chicken skin, amounting to $15 \%$ of broiler carcass. As chicken skin oil (CSO) is reported to contain unsaturated fatty acids, its application is being lost or underutilized. These fatty acids are known for its benefits in lowering blood cholesterol levels and reducing the risk of cardiovascular diseases [21]. Flaxseed (Linum usitatissimum L.), is one of the oldest cultivated crop and is widely accepted as a healthy food that has anticancer activity. The oil (FSO) primarily contains a good fatty acid profile of linolenic, linoleic, oleic, palmitic and stearic acids [22-25].

As these oils are reported to contain PUFA's, in the present study an attempt has been made to incorporate these oils in chitosan and carbopol gel bases and evaluate their efficacy for the treatment of burn wounds.

Analysis of oils using gas and high performance liquid chromatography following derivatization or acid hydrolysis of fatty acids is reported [26-29]. The paper also describes GC-MS analysis for the estimation of PUFAs in these oils.

\section{Materials and methods}

\section{Materials}

Black cumin oil (BCO) and flax seed oil (FSO) were purchased from local market (Mankarnika Aaushdhalaya, Pune, India). Chicken skin oil (CSO) was extracted in house. Glacial acetic acid (99\% AR) and toluene (99.5\% AR) were purchased from Lobachemie, Mumbai, India. Standard oleic acid (OA), sodium chloride, sodium bicarbonate, sulphuric acid (99.5\% AR), diethyl ether (99\% AR), carbopol-934, glycerin AR were purchased from Research Lab., Mumbai, India. Chitosan (deacetylation degree, approximately 75\%), methanol (HPLC grade) and $n$-hexane (HPLC grade) were procured from Himedia, Mumbai, India.

\section{Standardization of the oils}

The standardization of black cumin oil, chicken skin oil and flax seed oil were carried out as per standard procedures [30]. The measurement of each parameter was done in triplicate, average values were calculated and the same are reported.

\section{Quantitation of polyunsaturated fatty acids in oils}

Preparation of esters of fatty acids: Standard oleic acid and oil samples (up to $25 \mathrm{mg}$ ) were dissolved in toluene $(5 \mathrm{~mL}$ ) in separate round bottom flasks fitted with condenser. To each, $1 \%$ sulphuric acid in methanol $(10 \mathrm{~mL})$ was added and the mixtures were refluxed for 2 hours. After the specified period, sodium chloride solution $(5 \%, 25 \mathrm{~mL})$ was added and the prepared esters of fatty acids were extracted with $n$-hexane $(2 \times 25 \mathrm{~mL})$. The hexane layer was washed with water $(20$ $\mathrm{mL}$ ) containing potassium bicarbonate $(2 \%)$ and dried over anhydrous sodium sulphate. The solution was filtered and the solvent was removed under vacuum [31,32]. Standard esterified oleic acid was dissolved in $10.0 \mathrm{~mL}$ methanol to obtain standard solution of concentration $2500 \mu \mathrm{g} / \mathrm{mL}$. The esterified oil samples were also dissolved in $10.0 \mathrm{ml}$ methanol.

\section{Quantification of esters of oils by Gas Chromatography- Mass Spectrometric (GC-MS) analysis}

Esterified samples of oils were analyzed on Shimadzu GCMS system with OV-1 column $(25 \mathrm{~m} \times 3.3 \mathrm{~mm})$ using nitrogen as carrier gas to determine the composition of the different saturated and unsaturated fatty acids present. Ionization was carried out by electron impact ionization (70eV) [33]. The obtained GC-MS data was compared with standard mass spectral libraries to identify the PUFA's present in them.

\section{Preparation of gel formulations}

Preparation of chitosan gel formulation: As previously reported in the literature, chitosan solution of low and medium molecular weight was prepared in dilute acetic acid [34]. Chitosan powder (2\%, water soluble) was dissolved in $10 \mathrm{ml}$ glacial acetic acid AR $(2 \% \mathrm{v} / \mathrm{v})$. Glycerin AR $(10 \mathrm{ml})$ was added slowly to the above solution at room temperature with continuous stirring until formation of clear gel base. Formulated gel was kept overnight at room temperature to allow to swell. Then, fixed amount of black cumin, chicken skin oil and flax seed oil (approximately $265 \mathrm{mg}$ each) were added. The prepared gels were neutralized with $1 \mathrm{~N} \mathrm{NaOH}$ solution to $\mathrm{pH} 5$ and degassed at $25^{\circ} \mathrm{C}$ using a sonicator (Wensar ultrasonic water bath WUC-2L) to remove the air bubbles.

Preparation of carbopol-934 gel formulation: Carbopol-934 (0.9 $\% \mathrm{w} / \mathrm{w})$ was dissolved in glycerin AR $(3 \% \mathrm{v} / \mathrm{v})$, distilled water $(20 \mathrm{ml})$ and butyl hydroxyl tripthylate $(0.05 \% \mathrm{w} / \mathrm{w})$ using mechanical stirrer at $30 \mathrm{rpm}$ until clear solution was achieved. Methyl paraben $(0.18 \% \mathrm{w} / \mathrm{w})$ and propyl paraben $(0.02 \% \mathrm{w} / \mathrm{w})$ were added slowly to the above mixture [35]. To this, 2-3 drops of triethanolamine AR was added as a gelling agent at lower stirring speed. The formulated gel was kept overnight at room temperature to allow to swell. After 24 hours, fixed amount of black cumin, chicken skin oil and flax seed oil (approximately $265 \mathrm{mg}$ each) were added drop wise into the carbopol-934 gel with continuous stirring for $30 \mathrm{~min}$ to obtain a homogeneous mixture. Carbopol-934 gel was then neutralized to $\mathrm{pH} 5$ with polyethylene glycol- 400 .

Preparation of chitosan based hydrogel: Chitosan powder (2\% water soluble) was dissolved in a hot mixture containing lactic acid $(2 \% \mathrm{w} / \mathrm{v})$, propylene glycol-400 (10\% v/v) and glycerol-AR $(8 \% \mathrm{v} / \mathrm{v})$ 
as moistening agent with constant stirring using magnetic stirrer at moderate speed until chitosan and lactic acid completely dissolved. The prepared gel was kept in cool and dark place overnight at room temperature to swell. On the next day, previously triturated gelatin $(7.5 \% \mathrm{w} / \mathrm{v})$ and glycine $2 \%$ were added slowly with continuous stirring until formation of clear gel base. Finally, fixed amount of black cumin, chicken skin oil and flax seed oil (approximately $265 \mathrm{mg}$ each) were added drop wise into gel with continuous stirring. The prepared gels were neutralized with $1 \mathrm{~N} \mathrm{NaOH}$ solution to $\mathrm{pH} 5$ and degassed at $25^{\circ} \mathrm{C}$ using a sonicator (Wensar ultrasonic water bath WUC-2L) to remove the air bubbles.

\section{Evaluation of gel formulations [36]}

Visual examination: All the gel formulations were inspected for their homogeneity, colour, consistency; grittiness and phase separation by visual inspection after the gels were set in the containers.

pH measurement: The $\mathrm{pH}$ of the gel formulations was determined by using a digital $\mathrm{pH}$ meter (Systronics $\mathrm{pH}$ meter, Type 335) by dipping the glass electrode completely into gel solution system so as to cover the electrode. Then instrument reading in terms of $\mathrm{pH}$ was noted. The measurement of $\mathrm{pH}$ of each formulation was done in triplicate and average values were calculated.

Viscosity: The measurement of viscosity of the prepared gels was done with a Brookfield viscometer (model RVDV-II + pro) with spindle type S96, rotation speed of $0.5,1,2,4,5,10,20,50$ and $100 \mathrm{rpm}$ with sample volume of $20 \mathrm{ml}$ at temperature $37 \pm 0.5^{\circ} \mathrm{C}$. At each speed, the corresponding readings were noted ( $\mathrm{cPs}$ ). The measurement of viscosity of each formulation was done in triplicate and average values were calculated.

Spreadablity: The spreadablity of chitosan, carbopol-934 and hydrogel formulations was determined using a spreadablity apparatus which was fabricated in-house. The apparatus consisted of two glass slides $(7.5 \times 2.5 \mathrm{~cm})$, one of which was fixed onto the wooden board and the other was movable, tied to a thread which passed over a pulley, carrying a weight. $0.5 \mathrm{gm}$ gel formulations were placed between the two glass slides. 100 gm weight was allowed to rest on the upper slide for 1 to 2 minutes to expel the entrapped air between the slides and to provide a uniform film of the gel. The weight was removed and the top slide was subjected to a pull of $5 \mathrm{gm}$. The time necessary for top slide to travel the premarked distance of $6.5 \mathrm{~cm}$ was noted. This gave an idea of relative spreadablity of the different gels.

Rate of evaporation of water: It indicates the capability of the gels to maintain high humidity and water balance at the wound dressing interface. The prepared gel formulations were kept at $37 \pm 5^{\circ} \mathrm{C}$ and 70 $\pm 5 \%$ relative humidity. After regular intervals of time, the weight was noted. Weight percentage was found out by the equation:

Weight remaining $(\%)=\mathrm{W}_{\mathrm{t}} / \mathrm{W}_{0} \times 100$

Where, $\mathrm{W}_{0}$ and $\mathrm{W}_{\mathrm{t}}$ are initial weight and weight after time ' $\mathrm{t}$ ' respectively.

Film forming ability: The film forming ability of prepared gels were assessed by pouring $1 \mathrm{~g}$ of gel between two glass slides, maintained at $37 \pm 5^{\circ} \mathrm{C}$ and $70 \pm 5 \%$ relative humidity for $20 \mathrm{~min}$. The upper slide was then removed and the film forming ability of the gels were observed.

Percent flatness: The percent flatness was measured by cutting the film into five strips from the center of the film. The strips were cut so that each strip should be $4 \mathrm{~cm}$ in length and $0.5 \mathrm{~cm}$ in breadth.
Each strip was put on a clean surface without applying any additional pressure and length was measured by digital vernier caliper (Absolute Digimatic, Mitutoyo Japan). The percent flatness was calculated by the following formula.

Percent flatness $=\underline{(\mathrm{L} 1+\mathrm{L} 2+\mathrm{L} 3+\mathrm{L} 4+\mathrm{L} 5) / 5} \times 100$

4

Where

\section{L1, L2, L3, L4, L5- Length of the film}

Tensile strength: The tensile strength was measured by cutting the films formed into five strips from center of the films. The strips were cut so that each should be $4 \mathrm{~cm}$ in length and $0.5 \mathrm{~cm}$ in breadth. Tensile strength is calculated by dividing the load at break by the original minimum cross sectional area. The results are expressed in megapascals (MPa) and reported to three significant figures. The study was carried out under controlled conditions $\left(37 \pm 5^{\circ} \mathrm{C}\right.$ and $70 \pm 5 \%$ relative humidity).

Tensile strength $=($ Load at break $) /($ Original width $) \times($ Original thickness)

Stability testing of gel formulations: The prepared formulations were filled into aluminum collapsible tubes and the stability studies were carried out according to International Conference on Harmonization (ICH) guidelines Q1A. Short term accelerated stability study of prepared formulations were performed at $2^{\circ} \pm 0.5^{\circ} \mathrm{C}$ (Samsung refrigerator), $35^{\circ} \pm 0.5^{\circ} \mathrm{C}$ (Stability chamber, Arya Instruments, India), $65^{\circ} \pm 5^{\circ} \mathrm{C}$ (Remi CHM-16, India) for a period of 8 weeks. Samples were withdrawn at weekly intervals and analyzed for changes in visual appearance, clarity, $\mathrm{pH}$, spreadablity and viscosity [37].

\section{In-vivo wound healing study}

Animals: Male wistar rats, weighing 150-250 grams of the age of 3.0-4.0 months were used in the study. Animals were obtained from the National Toxicological Centre (NTC), Pune, India and were housed in animal place at room temperature being maintained at $25^{\circ} \pm 2^{\circ} \mathrm{C}$. Animals were fed on a standard pellet diet and kept under normal light/dark cycle. Animals were given free access to food and water. The experimental protocol was approved by the Institutional Animal Ethical Committee as per protocol number DYPIPSR/IAEC/1415/P-14 and conducted according to the Indian National Science Academy Guidelines for the use and care of experimental animals [38].

Burn wound healing model: The rats were randomly divided into 9 groups $(n=6)$. The back of each rat was shaved under ketamine anesthesia and prepared for operation. There after open circular wound of $300 \mathrm{~mm}^{2}$ areas was produced in each rat by pouring hot molten wax at $80^{\circ} \mathrm{C}$ into a metal cylinder with $300 \mathrm{~mm}^{2}$ circular opening, placed on the back of each animal. Group 1 (normal group) animals were not subjected to the burn wound formation, Group 2 (control group) where animals were wounded but received no treatment, Group 3(standard treated group) where animals were treated with standard silver sulfadiazine cream $(0.5 \%)$, whereas groups 4,5 and 6 (experimental gel base groups) animals received treatment of plain gel bases such as chitosan, carbopol-934 and hydrogel base. Animals of groups 7-9 (experimental gel bases with combination of oils) were treated with gel bases incorporated with black cumin oil, chicken skin oil and flax seed oil in equal ratios. Groups 2-9 were treated once daily for a period of 21 days. The animals were kept in separate cages and were provided standard diet and water ad libitum throughout the study. The rate of 
wound contraction and period of epithelisation were noted. At the end of the study, the animals were sacrificed and wound tissue mass was obtained from the wound area by sharp dissection [39,40].

\section{Evaluation of wound healing}

Epithelization period: Percentage of wound re-epithelization was determined by image analysis. The distance from right wound margin to left wound margin was measured. The length of newly generated epithelium across the surface of the wound was determined as the sum of the new epidermis growing from right to left margin of the wound. This length was expressed as a percentage of entire wound length. It was monitored by noting the number of days required for scar to fall away, leaving no raw wound behind.

Wound contraction: To monitor wound contraction, progressive changes in wound area were measured by using digital vernier calliper. From this, wound areas were read and the percentage of wound contraction was calculated taking the initial size of wound $\left(300 \mathrm{~mm}^{2}\right)$ as $100 \%$.

Wound size reduction $(\%)=\left[\mathrm{A}_{0}-\mathrm{A}_{\mathrm{t}}\right] / \mathrm{A}_{0} \mathrm{x} 100$

Where $\mathrm{A}_{0}$ and $\mathrm{A}_{\mathrm{t}}$ are initial wound area and wound area after a time interval' $\mathrm{t}$ '.

Histological study: To confirm the maturity of the healed tissues or those with marked improvements, histological examination was carried out. The wound tissue specimens were processed in $5 \%$ formalin solution embedded in paraffin. A section of 3-5 $\mu \mathrm{m}$ obtained from each paraffin block was stained with haematoxylin and eosin ( $\mathrm{H} \& \mathrm{E}$ ) for routine histological processing. The prepared slides were examined qualitatively under a light microscope, for examining hair follicle, inflammation, blood vessels, fibroblast, necrosis, bacterial colonies, neutrophils, edema and collagen.

\section{Statistical analysis}

Statistical analysis was performed with Dunnett's test and computation was performed using GraphPad InStat version 3.01 using ANOVA, assuming confidence level of $95 \%$ with ${ }^{*} \mathrm{p}<0.05$ and ${ }^{* *} \mathrm{p}<$ 0.01 for statistical significance. All the data were expressed as mean \pm standard deviation.

\section{Results}

\section{Standardization of the black cumin oil, chicken skin oil and flax seed oil}

The standardization of black cumin oil, chicken skin oil and flax seed oil carried out as per standard procedures showed that the experimentally obtained values for various physicochemical parameters were within the range as specified in standard texts confirming the purity of the oils (Table 1).

Quantification of oleic acid in esterified sample of black cumin, chicken skin oil and flax seed oil

Gas Chromatography-Mass Spectrometric analysis of esterified standard and oil samples

\section{Oleic acid ester}

The GC-MS analysis of standard oleic acid ester showed a sharp peak eluting at $21.880 \mathrm{~min}$. with $\mathrm{m} / \mathrm{e} 296$ characteristic of oleic acid (Figure 1). Additional peaks at m/e 270 (RT $19.275 \mathrm{~min}$.) and m/e 294
(RT 21.813 min.) were observed which on comparison with standard mass spectral libraries indicated the presence of methyl ester of palmitic acid and linoleic acid respectively. However, the \% of oleic acid was found to be significantly high $(86.31 \%)$ with low amounts of palmitic (3.87\%) and linoleic acid (9.82\%).

\section{Esterified samples of black cumin oil}

The GC-MS chromatogram of esterified sample of black cumin oil showed a peak at RT $19.281 \mathrm{~min}$ (Figure 2). with m/e 270 which matches to the $\mathrm{m} / \mathrm{e}$ of standard palmitic acid when compared with standard mass spectral libraries. The sample showed two additional closely spaced peaks at $21.819 \mathrm{~min}$. and $21.879 \mathrm{~min}$. with m/e 294 and 296 respectively. Comparison with standard mass spectral libraries indicated the presence of methyl ester of linoleic acid and oleic acid respectively (Table 1 ). Also a peak appeared at $\mathrm{m} / \mathrm{e} 312$ characteristic of the presence of ricinoleic acid $(1.43 \%)$. The $\%$ content of palmitic acid and linoleic acid was found to be $22.87 \%$ and $23.14 \%$ respectively.

\section{Esterified samples of chicken skin oil}

The GC-MS of esterified samples of CSO exhibited peaks at 19.281 min. (m/e 270), $21.819 \mathrm{~min}$. (m/e 294), $21.879 \mathrm{~min}$. (m/e 296) and 23.738 min. (m/e 312) (Figure 3). The mass spectral matching indicated the presence of methyl esters of palmitic acid (13.98\%), linoleic acid (47.47\%), oleic acid (25.67\%) and ricinoleic acid (3.28\%) respectively (Table 1).

Esterified samples of flax seed oil: In the GC-MS analysis of esterified sample of flax seed, five peaks were recorded in the chromatogram at RT $18.279 \mathrm{~min}$. (m/e 270), $20.647 \mathrm{~min}$. (m/e 294), $20.750 \mathrm{~min}(\mathrm{~m} / \mathrm{e} 292)$, and $21.017 \mathrm{~min} .(\mathrm{m} / \mathrm{e} 298)$ and $23.125 \mathrm{~min} .(\mathrm{m} / \mathrm{e}$ 312) (Figure 4). The mass spectral data indicated the presence of methyl esters of palmitic acid (10.09\%), linoleic acid (13.71\%), linolenic acid (51.86\%), stearic acid (11.29\%) and ricinoleic acid (3.51\%) respectively, when compared with standard mass spectral libraries (Table 1).

\section{Formulation and evaluation of gels}

Literature reports indicate that a study carried out by Pereira L.M. et al. demonstrated that treatment with topical application of $300 \mu$ of pure oleic acid (equivalent to $268.5 \mathrm{mg}$ ) resulted in pro-inflammatory effect as indicated by the increase in wound mass, protein and DNA contents and neutrophil migration to wound tissue in experimental rats. Based on these observations, in the present study, it was decided to incorporate a fixed amount of each oil ( $265 \mathrm{mg}$ ) in the gel bases. Accordingly, gel formulations employing chitosan, carbopol-934 and chitosan based hydrogel were prepared successfully using fixed amount of oils.

Initially sufficient trials were undertaken to evaluate the influence of $\%$ of polymeric matrices to induce gel formation. Accordingly gel

Table 1. Analysis of black cumin oil, chicken skin oil and flax seed oil.

\begin{tabular}{|c|c|c|c|}
\hline Parameters & Black cumin oil & Chicken skin oil & Flax seed oil \\
\hline Refractive index & $1.49 \pm 0.856$ & $1.521 \pm 0.786$ & $1.466 \pm 0.044$ \\
\hline Specific gravity & $0.8617 \pm 0.008$ & $0.9717 \pm 0.011$ & $0.9813 \pm 0.005$ \\
\hline \begin{tabular}{c} 
Iodine value (g/100g) \\
\hline $\begin{array}{c}\text { Acid value } \\
\text { (mg KOH/g) }\end{array}$
\end{tabular} & $113.78 \pm 0.2928$ & $70 \pm 0.884$ & $173.65 \pm 1.229$ \\
\hline Saponification value & $172.35 \pm 0.881$ & $197 \pm 1.058$ & $194.19 \pm 1.452$ \\
\hline $\begin{array}{c}\text { GC-MS } \\
\text { \% Oleic acid }\end{array}$ & 36.36 & 25.67 & 11.29 \\
\hline \% Palmitic acid & 22.87 & 13.98 & 10.09 \\
\hline \% Linoleic acid & 23.14 & 47.47 & 13.71 \\
\hline \% Linoleneic acid & - & - & 51.86 \\
\hline
\end{tabular}

"Values are mean of three recordings 


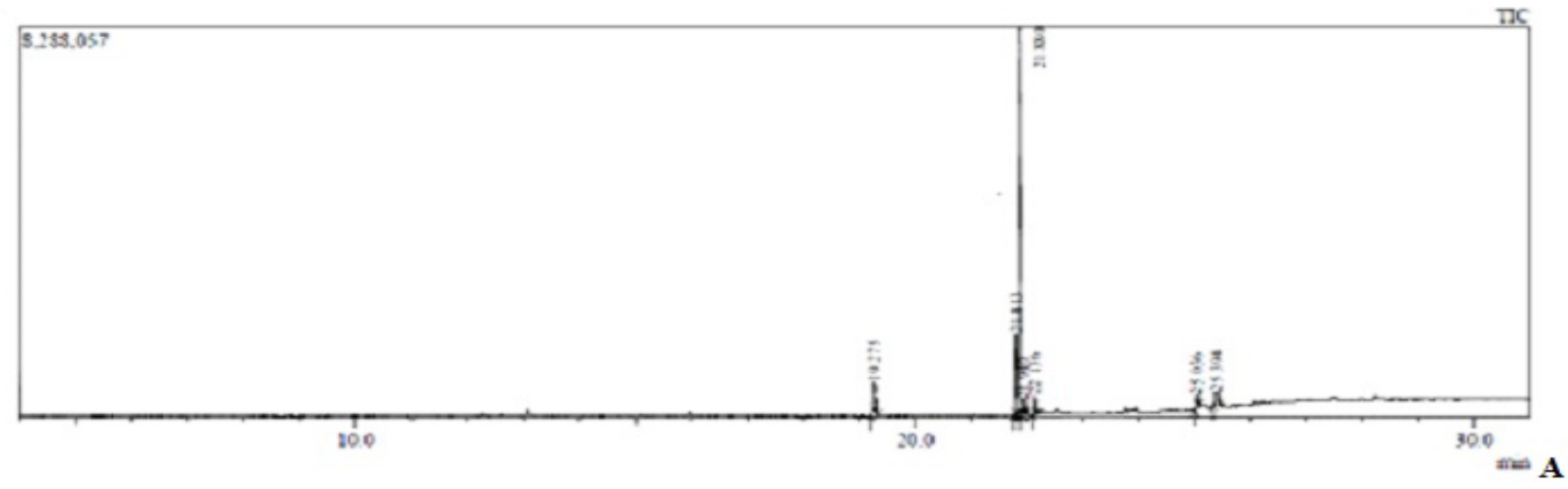

Hitt:2 Entry.115413 LibraryNSST11.ib

SI:90 Formula:C19H3602 CAS:2777-584 MollWeight:296 Rethndex:2085

CompName:6-0ctadecenoic acid, methyl ester, (Z) \$ \$ Methyl cis-6-octadecenoate S\$ Methyl petroselinate S\$ Methyl (6Z)-6-octadecenoate \# S\$ cis-6-0cta

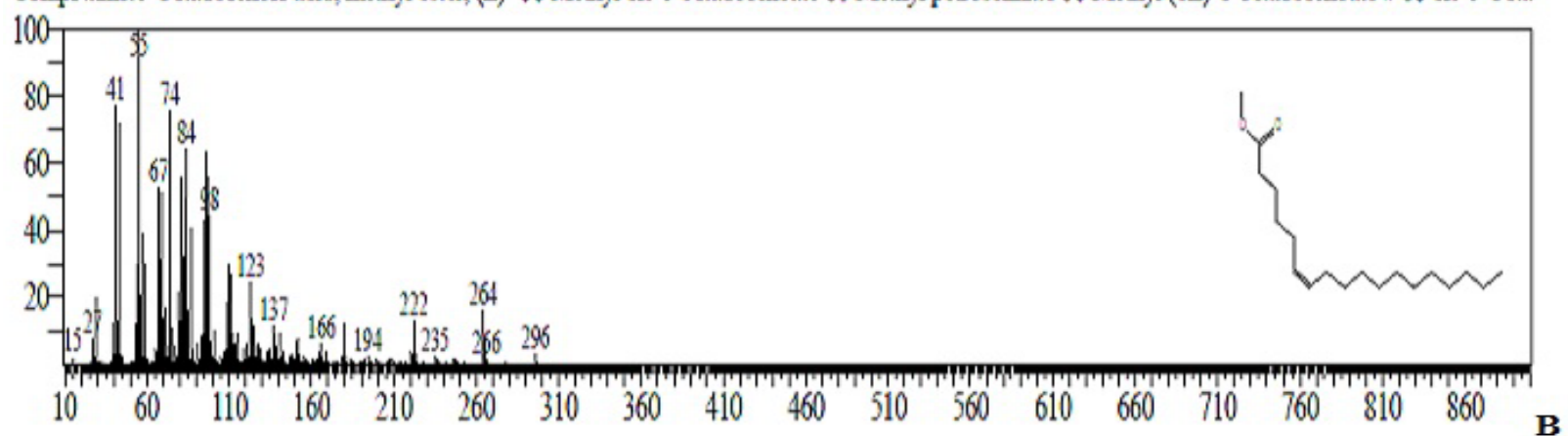

Figure 1. (A) Chromatogram of ester of oleic acid. (B) Mass fragmentation pattern of peak eluting at $21.88 \mathrm{~min}$. (m/e 296).

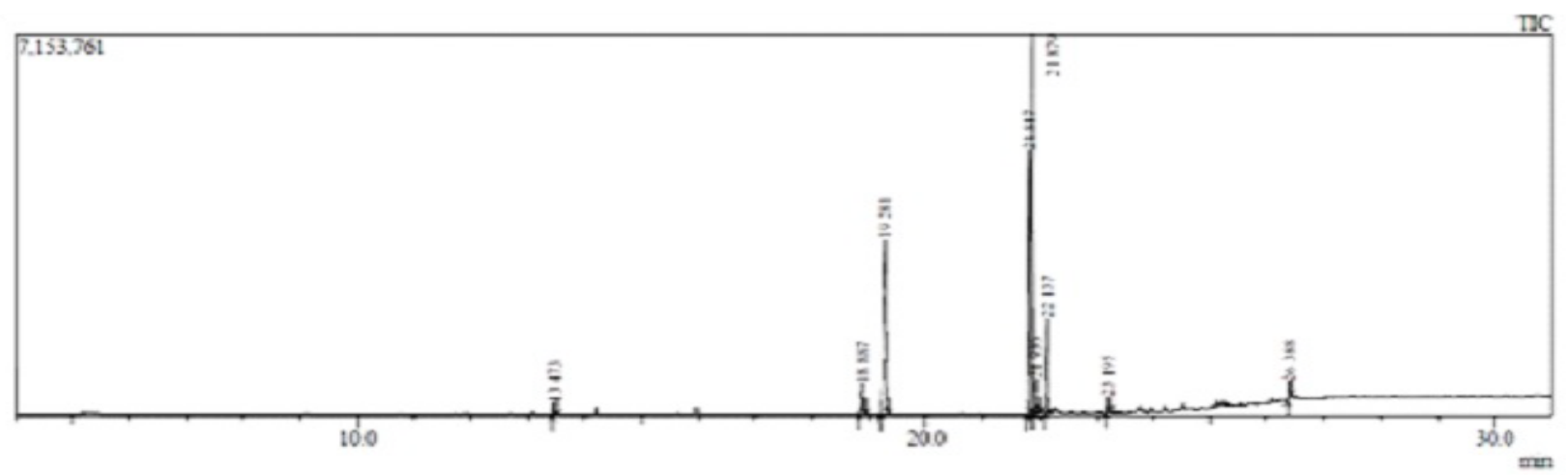

A

Hit=1 Enryl15419 Liman:NSTI1.bo

S1-94 FomulaC19H3602 CAS-1937-62-8 Mollieight-296 Rethdex-2085

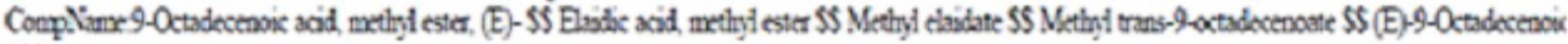

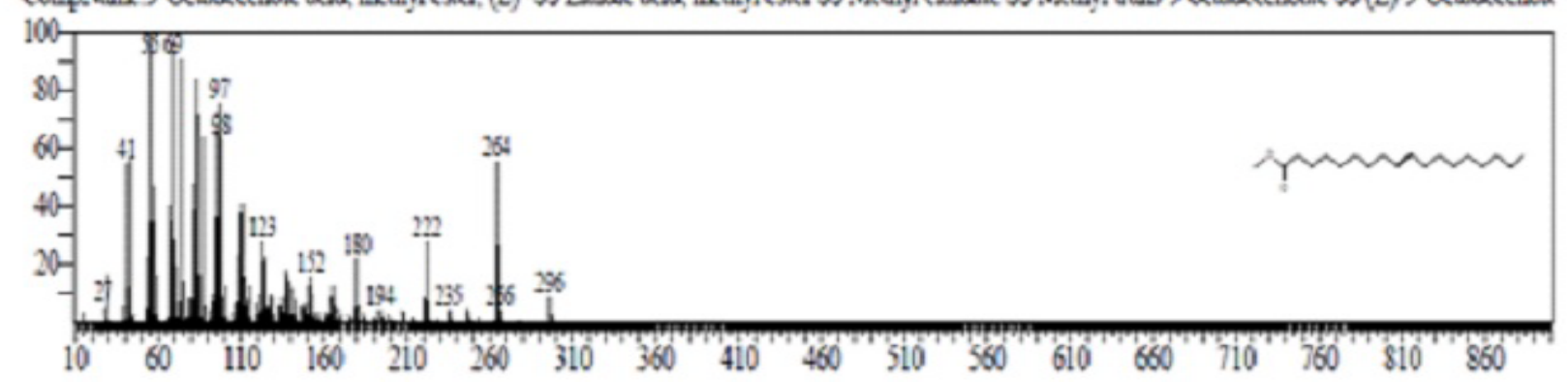

B

Figure 2. (A) Chromatogram of ester of Black cumin oil. (B) Mass fragmentation pattern of peak eluting at $21.879 \mathrm{~min}$. (m/e 296) 


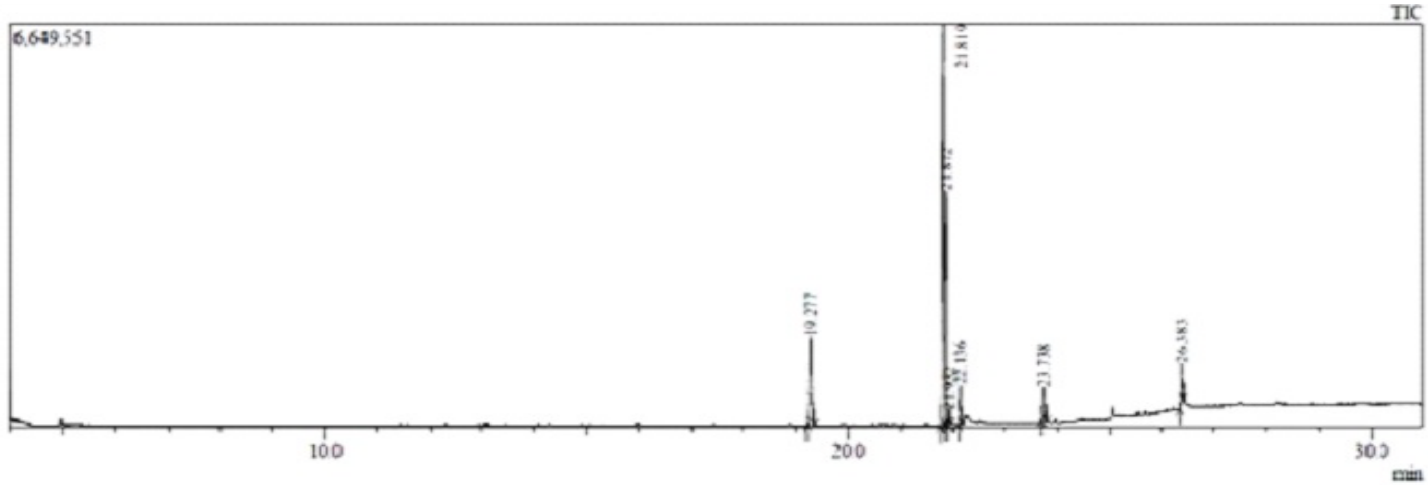

$\mathbf{A}$

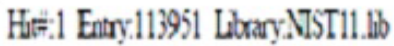

S195 Fomula:C19H3402 CAS:112-63-0 Mollieight:294 Relindex:2093

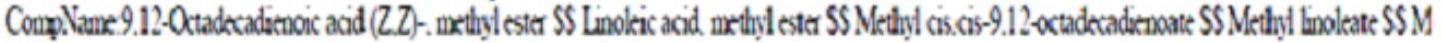

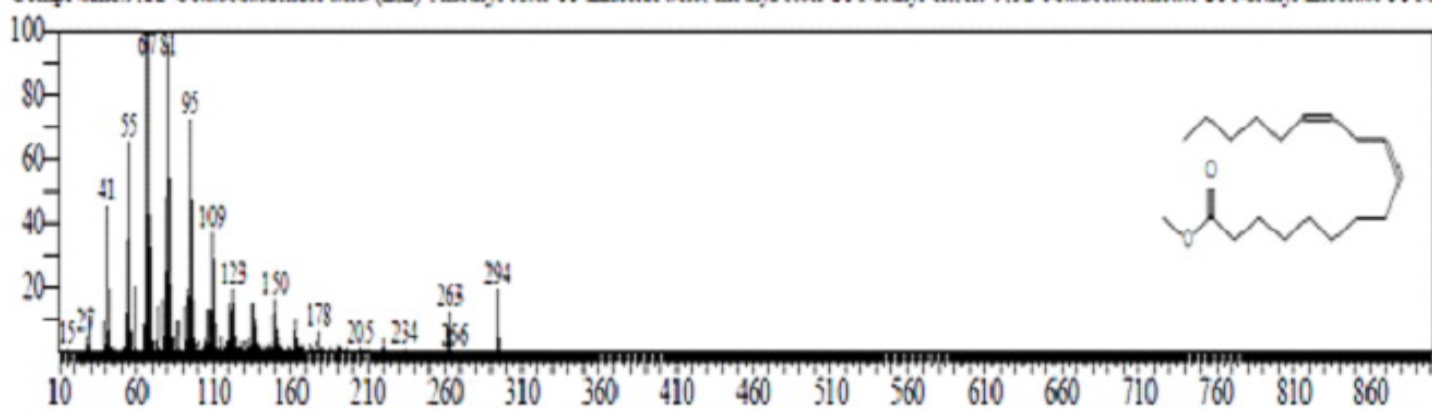

$\mathbf{B}$

Figure 3. (A) Chromatogram of Ester of Chicken skin oil. (B)Mass fragmentation pattern of peak eluting at $21.819 \mathrm{~min}$. (m/e 294).

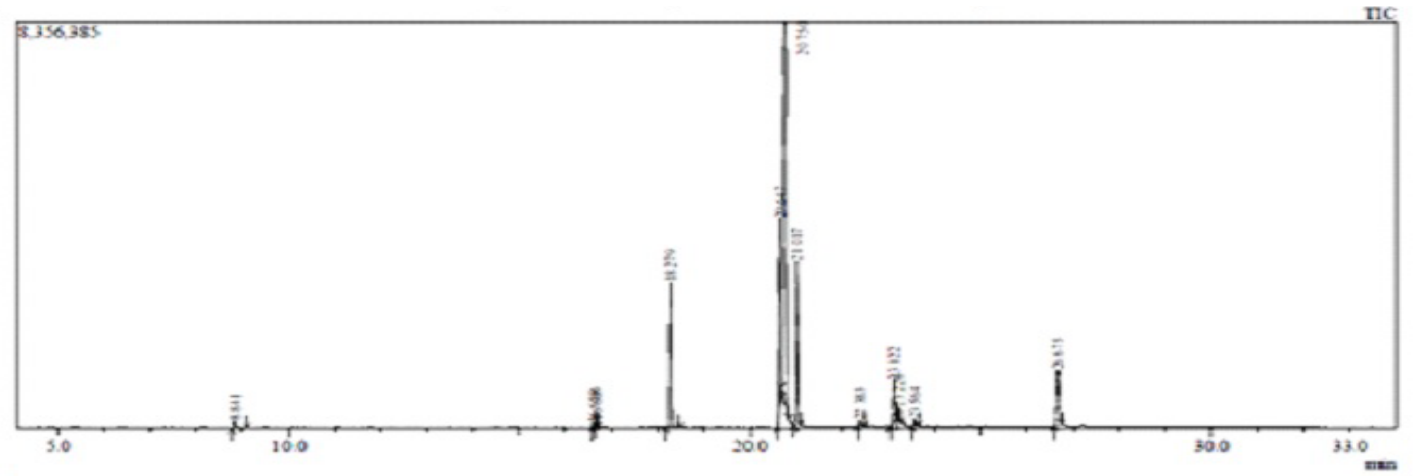

A

Hele 5 Enry:25702 Lorary:TST11s bo

S184 FomulaC19H3202 CAS301-00-8 Mollieight292 Rethdex2101

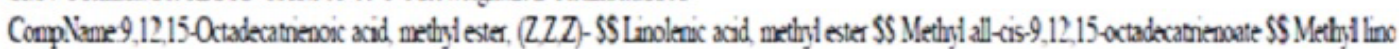

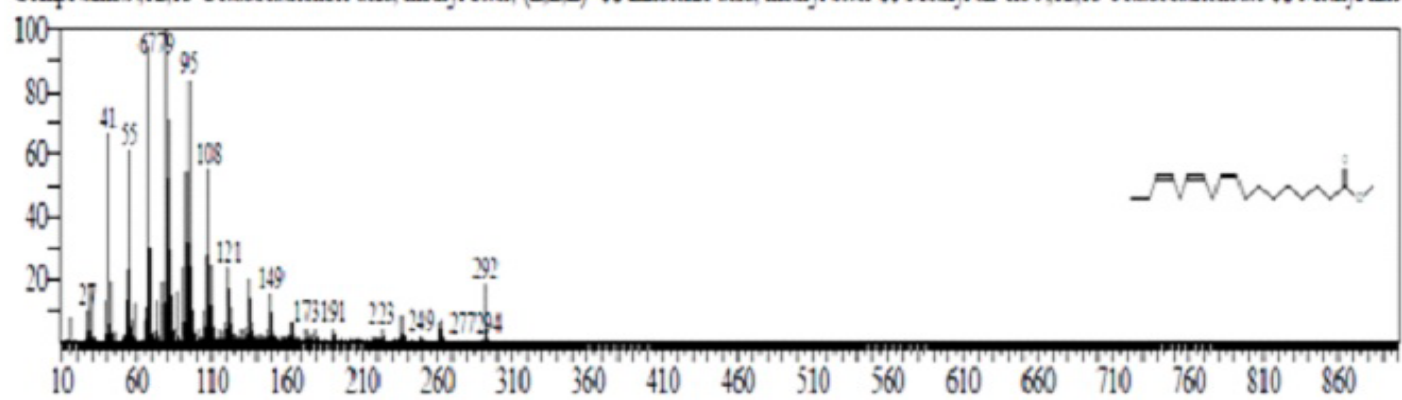

$\mathbf{B}$

Figure 4. (A) Chromatogram of Ester of flax seed oil. (B) Mass Fragmentation pattern of peak 20.750 (m/e 292) 
bases were prepared using $1 \%$ and lower concentration of chitosan. However, the spreadability and viscosity of these gels were too low and resulted in increased time for film formation. In case of gels prepared using carbopol-934, $0.5-0.8 \%$ carbopol base resulted in poor gel formation with inability to adhere to the site of application.

It was observed that chitosan at a concentration of $1.5-2 \mathrm{w} / \mathrm{w} \%$ (B1) and carbopol-934 at a concentration of $0.9 \%$ (B2) was effective in preparing gel bases with required viscosities and spreadability and was selected for further studies. In case of hydrogel formation, chitosan $2 \%$ with gelatin $7.5 \%$ was employed (B3). Incorporation of oils in the prepared gel bases produced slightly yellow coloration with $\mathrm{pH}$ at 5.2 which is within the acceptable $\mathrm{pH}$ range (5 - 5.5) for topical preparations (Table 2).

\section{Rate of evaporation of water from gel formulation}

The gel formulations showed different rate of evaporation at different intervals of time. It was found that formulations F1, F2 and F3 lost water at the rate of $13.66 \mathrm{gm} / \mathrm{m}^{2}, 20.66 \mathrm{gm} / \mathrm{m}^{2}, 21.84 \mathrm{gm} / \mathrm{m}^{2}$ respectively at $5 \mathrm{hrs}$ of the study. The chitosan hydrogel formulation F3 exhibited improved rate of water evaporation as compared to F1 and F2. It is clear from the studies that the materials will lose water content when exposed to air under dry conditions over long periods.

\section{Film forming ability}

In the present study, the chitosan film prepared from $2 \mathrm{~g}$ chitosan in $2 \%$ acetic acid (F1) showed thickness of $0.17 \mathrm{~mm}$. In comparison, the hydrogel formulation F3 containing chitosan formed film of slightly increased thickness $(0.20 \mathrm{~mm})$ which may be due to presence of gelation. On the other hand F2 failed to form film which might be due to its low and middle degree of cross linking. However, it was effective in maintaining a protective and moist environment over the wound area which is important for the wound healing process.

\section{Percent flatness and tensile strength of the films}

Films formed from F1 and F3 showed percent flatness of $36.052 \pm$ 0.3808 (97\%) and $39.43 \pm 0.1999$ (99\%) respectively. Correspondingly, tensile strength was found to be $52.73 \pm 0.868$ and $52.52 \pm 7.221 \mathrm{Mpa}$ respectively (Table 2). The films formed are elastic, non-toxic, nonantigenic, biocompatible and biodegradable. Hence, it helps to protect the burn wound from the external environment thereby minimizing infection.

\section{Stability studies}

The stability studies of the formulations carried out at $2^{\circ} \mathrm{C} \pm 0.5^{\circ} \mathrm{C}$, $37^{\circ} \mathrm{C} \pm 0.5^{\circ} \mathrm{C}$ and in open environment showed that the gels did not exhibit any significant changes in visual appearance with null phase

Table 2. Evaluation of gel formulations F1, F2 and F3.

\begin{tabular}{|c|c|c|c|}
\hline $\begin{array}{l}\text { Evaluation } \\
\text { parameters }\end{array}$ & $\begin{array}{c}\text { Chitosan gel } \\
\text { formulation(F1) }\end{array}$ & $\begin{array}{c}\text { Carbopol-934 } \\
\text { gel formulation(F2) }\end{array}$ & $\begin{array}{c}\text { Hydrogel } \\
\text { formulation(F3) }\end{array}$ \\
\hline Physical Appearance & $\begin{array}{c}\text { Yellowish, } \\
\text { homogeneous greasy }\end{array}$ & $\begin{array}{l}\text { White to yellow, } \\
\text { homogeneous, non } \\
\text {-greasy }\end{array}$ & $\begin{array}{l}\text { Dark yellow, } \\
\text { Homogeneous, } \\
\text { Slightly greasy }\end{array}$ \\
\hline Phase separation & Nil & Nil & Nil \\
\hline $\mathrm{pH}^{* *}$ & $5.2 \pm 0.055$ & $5.2 \pm 0.042$ & $5.3 \pm 0.033$ \\
\hline Spreadablity ${ }^{* *}$ & $35 \pm 1.202$ & $29 \pm 2.258$ & $40 \pm 3.324$ \\
\hline Percent flatness ${ }^{* * *}(\mathrm{~mm})$ & $36.052 \pm 0.3808$ & - & $39.43 \pm 0.1999$ \\
\hline $\begin{array}{c}\text { Tensile strength }{ }^{* *} \\
(\mathrm{mPa})\end{array}$ & $52.73 \pm 0.8685$ & - & $52.22 \pm 7.221$ \\
\hline Stability studies ${ }^{* *}$ & Stable & Stable & Stable \\
\hline
\end{tabular}

${ }^{* *}$ Values are Mean \pm SEM of three recordings separation and were intact with no leakage during the period of six weeks at specified temperature ranges (Table 2).

\section{Wound healing studies of gel formulation}

In this exploration, treatment efficacy of gel bases B1-B3 and formulated topical gel preparations F1-F3 on rats with burn wound was investigated in comparison to standard silver sulfadiazine $0.5 \%$ gel formulation (Figures 5-7).

All the treated groups showed significant difference in the wound contraction compared to the control group (untreated group) after day 3 of the study period. Continuation of treatment till the end of 21 days, resulted in significant reduction in wound size in the standard treated (Group 2), gel bases treated groups (Groups 3-5) and groups 6-8 treated with gel bases incorporated with the test oils which are rich in polyunsaturated fatty acids like oleic, linoleic and linolenic acid. Comparison of the efficacy of the gel base treated groups with those receiving the test formulation containing oils, it was observed that the formulation F2 treated group containing the oils in carbopol base exhibited more significant differences in wound contraction (F2, $32.72 \%$ on day $9, \mathrm{p}<0.01 ; 40.28 \%$ on day 12 of the study, $\mathrm{p}<0.01$ ) as compared to the gel base (B2, $20.64 \%$ on day $9 ; 32.71 \%$ on day 12 of the study, $\mathrm{p}<0.01)$. At the end of the treatment period (21 days), significant marked improvement (contraction in wound size) was observed in the animals treated with chitosan $(69.245 \%, \mathrm{p}<0.01)$, carbopol $(72.66 \%$ $\mathrm{p}<0.01)$ and chitosan hydrogel $(70.84 \%, \mathrm{p}<0.01)$ systems containing the oils when compared to the gel base treated groups (chitosan gel base: $54.37 \%$; carbopol gel base: $56.40 \%$ and chitosan hydrogel base: $56.50 \%, \mathrm{p}<0.01$ ). The formulation treated groups (Groups 6-8) also were more efficious in reducing the wound size as compared to the standard group receiving $0.5 \%$ silver sulfadiazine $(61.3 \%$ on day 21 of the study, $\mathrm{p}<0.01)$.

The time for epithelization was measured from day 1 of the study. The epithelisation time was found to be significantly lower in group 3 treated (Standard SSD 0.5\%) and in F2 treated groups (17 \pm 0.8214 days, $17 \pm 1.102$ days respectively). However F1 and F3 treated groups required $19 \pm 1.44$ days and $19 \pm 0.96$ days to heal, about two days longer than the standard SSD $0.5 \%$ and F2 treated groups. Mean time for reepithelization of B1, B2 and B3 treated groups were $25 \pm 1.721,23$ \pm 0.766 and $24 \pm 0.770$ days respectively, around 8-9 days longer than standard SSD $0.5 \%$ treated and 12 days longer than control group (29 \pm 0.5685 days).

\section{Histopathological studies}

Histopathological examinations of the healed wounds are shown in Figure 6. Hematoxylin and eosin ( $\mathrm{H}$ and $\mathrm{E})$ stains which stain collagen fibers pale pink, cytoplasm purple, nuclei blue, RBC (red blood cells) cherry red were used in the study.

The intensity of inflammatory response, bacterial colonies was moderately severe with low fibroblast and collagen disposition in control group than the base and combination treated groups. Besides, on the 21 st day after wound creation, all groups of experimental rats showed epithelisation of the wound area, regarding to the collagenisation, blood vessel formation, hair follicle growth and neutrophils. The formulations F1, F2 and F3 containing the oils in chitosan, carbopol-934 and hydrogel bases presented intense disposition of gross thick parallel arranged collagen bundles with little or no scar deposited on the top. This study helps to confirm the literature reports that suggest the significant role of oleic acid in down regulating cyclooxygenase 2 (COX-2), inducing collagen type III expression thereby accelerating the wound healing 


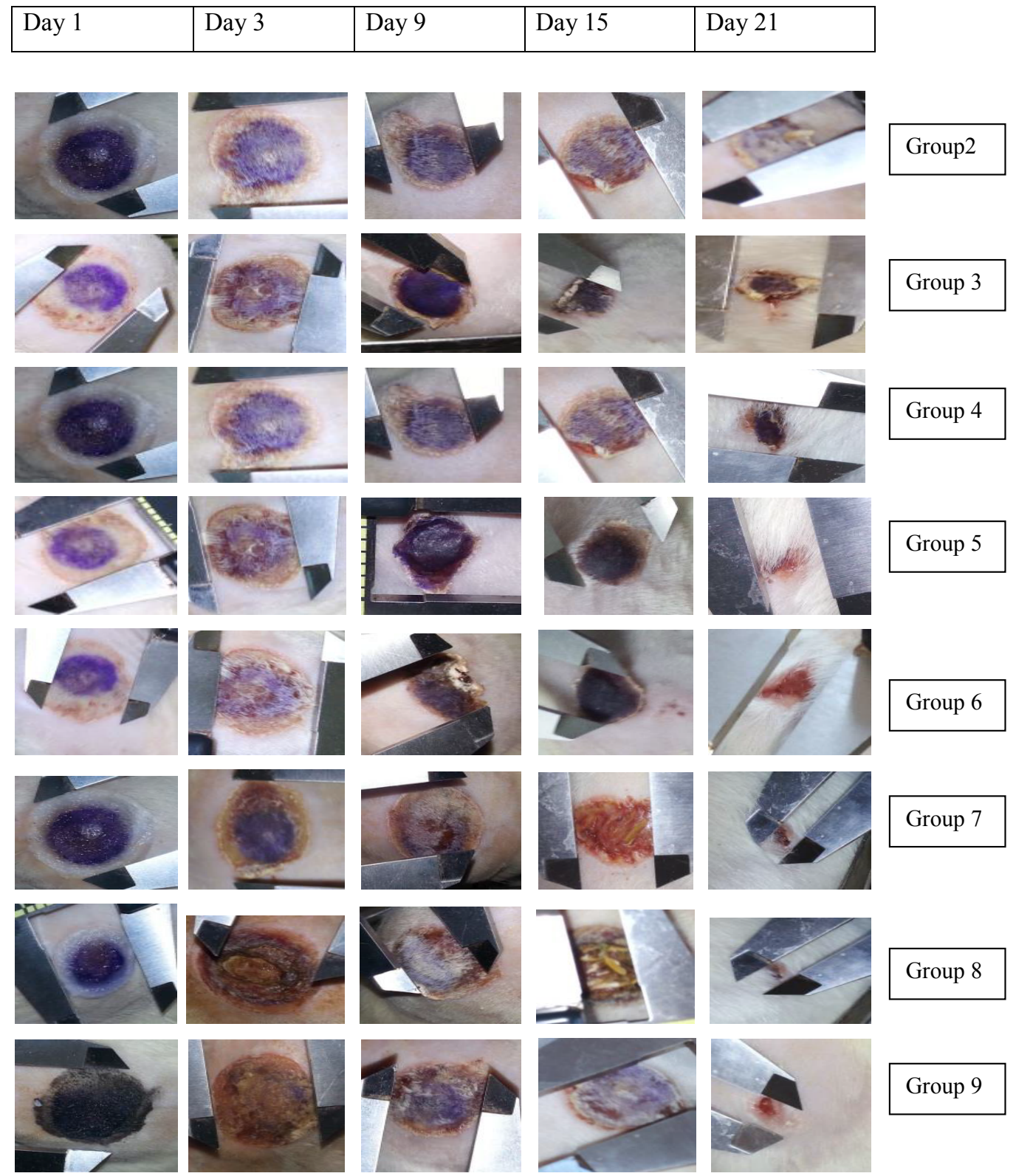

Figure 5. Photographic images of the wound healing area over a period of 21 days. Burn wound with $300 \mathrm{~mm}^{2}$ diameter were induced at the dorsal skin of each wistar rats. The images were taken after the 1,3,6,9,12,15,18, and 21 days of the injury. Group 2: diseased control, Group 3: treated with standard SSD (0.5\%), Group 4: B1, Group 5: B2, Group 6: B3, Group 7: F1, Group 8: F2 and Group 9: F3.

process. The standard silver sulfadiazine $(0.5 \%)$ treated group showed the same mix of highly interlaced collagen fibers but the fiber seemed to be thinner in arrangement that resembled the normal dermis.

\section{Discussion}

Natural oils rich in PUFA's like black cumin, chicken skin and flax seed oils were incorporated in chitosan and carbopol gel bases. The GC-MS analysis of the oils indicated the presence of saturated fatty acid like palmitic acid and stearic acid. Palmitic acid was present in $\mathrm{BCO}, \mathrm{CSO}$ and FSO. However stearic acid was found only in FSO. Polyunsaturated fatty acid i.e. linoleic acid, oleic acid and ricinoleic acid were present in BCO, CSO and FSO. However, a major amount of linolenic acid was additionally present in FSO. From the GC-MS data it is observed that oleic acid $(36.36 \%)$ is present in higher amounts in BCO when compared to CSO $(25.67 \%)$. A higher \% of linoleic acid was found to be present in CSO, when compared to BCO and FSO. In contrast, FSO showed greater amount of linolenic acid $(51.86 \%)$. CSO exhibited an overall superior polyunsaturated fatty acid profile as compared to BCO and FSO.

Gel formulations employing Chitosan (F1), carbopol-934 (F2) and chitosan based hydrogel (F3) were prepared successfully using fixed amount of oils. The viscosity of gel bases determined at various shear rates showed that as the shear rate increased the viscosity of gel bases decreased. Also, increase in polymer concentration attributed to increase in viscosity of the formed gels. Gel bases B1 and B3 exhibited classic shear-thinning or pseudoplasticity as the viscosity returned 


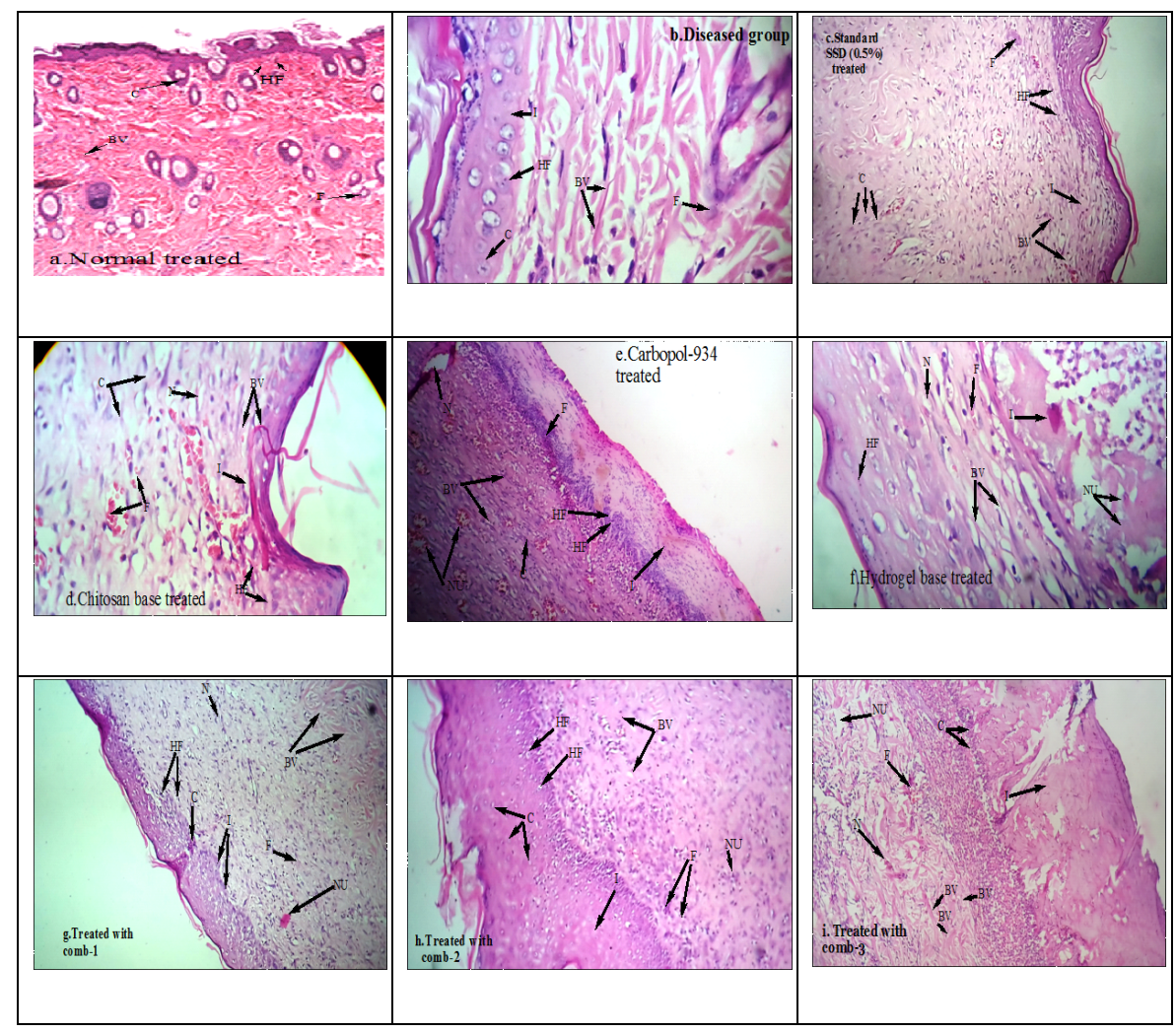

Findings: BV-blood vessels, HF-Hair follicles, C-Collagen disposition, I-Inflammation, F-Fibroblast, N-Necrosis and NU-Neutrophils.

Figure 6. Photomicrograph showing histopathological changes of healed skin wounds on day 21 of postwounding (stained with Heamatoxyline and eosin). a. Normal treated. b. Diseased state. c. Standard group, d. Chitosan gel base treated. e. Carbopol-934 gel base treated, f. Hydrogel base treated, g. Formulation F1 treated. h. Formulation F2 treated. i. Formulation F3 treated.

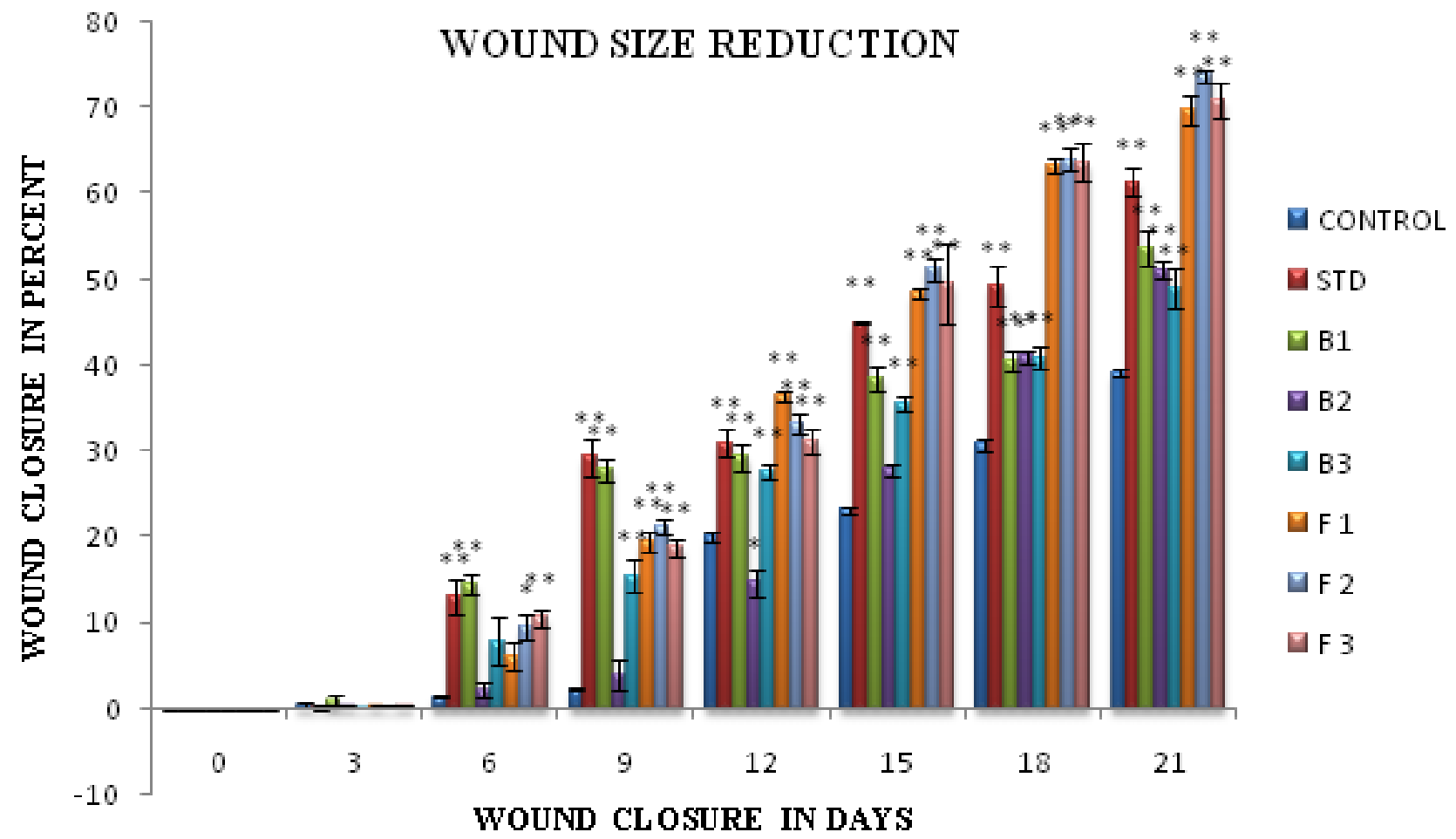

Statistical analysis, using one way ANOVA followed by Dunnett's test for multiple comparision expressed as mean \pm SEM values. (*p $<0.05, * * p<0.01$ ).

Figure 7: Wound closure in percent. Statistical analysis, using one way ANOVA followed by Dunnett's test for multiple comparision expressed as mean \pm SEM values. $\left(* \mathrm{p}<0.05,{ }^{* *} \mathrm{p}<0.01\right)$. 
to normal as soon as the shear was removed. However, B2 took a measurable time for the viscosity to recover, indicating shear-thinning with thixotropic behavior. However, the viscosities of all the gel bases were appreciable and contributed to the product adhesiveness.

Venkatesh et al. clearly reported that carbopol-934 and chitosan by its inherent property of bioadhesion and high biodegradability adhere to biomembrane, thereby proving beneficial in prolongation of the loss of water at site of application [41]. The oils were evenly distributed into the gel bases and did not exhibit any phase separation. This ensures that the required amount of drug is available on each application, thereby maximizing the benefits from the oils. Loveleen P. K. and Guleri T. $\mathrm{K}$. has suggested that the therapeutic potency of gel formulation is dependent on its spreading capacity [42]. It was observed that the spreadablity time of prepared formulations F1- F3 were 35, 29 and 40 sec respectively in conjunction with non-greasy, null phase separation with increased viscosity which are important criteria for film forming and gel adheration on wound surface. The improved rate of water evaporation of $\mathrm{F} 3$ as compared to $\mathrm{F} 1$ and F2 demonstrates its ability to uptake exudates and edematous fluids from the wound area into the dressing by an active upward-directed process when used in exudating wounds. Clearly, these gel dressings will be more beneficial to treat wounds with moderate exudates rather than for dry wounds.

The formulated topical gel preparations F1-F3 in the burn wound model in rats demonstrated the positive effect of the use of natural oils containing polyunsaturated fatty acids to accelerate the wound healing process. Additionally, the bacteriostatic, anti-inflammatory, antioxidant properties of chitosan with skin tissue regeneration capacity and anti-inflammatory potential of carbopol may have contributed positively for the enhanced activity [43].

In the histopathological examinations, as compared to the control group, a remarkable content of large spindle shaped cells interpreted as active fibroblasts, mainly in the bottom of the healing area, was observed, particularly in the standard silver sulfadiazine treated and combinations treated group 7-9. In addition, the development of delicate network of slit capillary blood vessels forming an immature granulation tissue was observed in chitosan, carbopol-934 and hydrogel base treated groups with nonappearance of bacterial colonies.

The control group exposed a loose irregular arrangement of collagen fibers and blood vessels with large dissociating areas in between epithelial tissue indicating that the healing process is incomplete and still active. The histopathological examinations and interpretations indicate the significant anti-inflammatory potential, skin tissue regeneration and wound closure capabilities of black cumin oil, chicken skin oil and flax seed oil. The oils were also found to be superior in promoting the formation of the collagen and accelerating reepithelisation in less time with good probability for reducing scar formation compared to standard silver sulfadiazine $(0.5 \%)$. This may be due to polyunsaturated fatty acid profile of the oils incorporated in the formulations F1-F3. Oleic and linoleic acid present in moderate amount in $\mathrm{BCO}$ and $\mathrm{CSO}$ and which have been previously reported to produce a marked increase in the neutrophil migration to the wound healing area stimulating the release of vascular endothelial growth factor-alpha (VEGF-a), interleukin-1beta (IL-1b), and CINC-2a/b (cytokine-induced neutrophil chemoattractants in inflammation) may be responsible for the marked activity. Also other essential fatty acids (EFA) such as linolenic acid (in high amount in FSO) and ricinoleic acids (in low amounts in all oils) and which have proved to be necessary for the maintenance of epidermal integrity in the skin with remarkable anti-inflammatory effects may have contributed to the enhanced effects.

\section{Conclusion}

Topical gel preparations employing biodegradable chitosan and carbopol-934 bases incorporated with natural oils like black cumin oil, chicken skin oil and flaxseed oils rich in PUFA's have been successfully prepared for use in treatment of burn wounds. Comparative evaluation of the prepared gel formulations suggests that the chitosan based hydrogels system exhibited excellent film forming ability, greater bioadhesiveness thereby minimizing the frequency of application with improved patient compliance. The hydrogel formulation also facilitated greater moisture and water vapor permeability, enabling its capacity to uptake exudates and edematous fluids from the wound into the film formed, supporting its application in exudating wounds. The formulation containing the natural oils rich in polyunsaturated fatty acids like oleic, linolenic, linolenic and ricinoleic acid accelerated the wound healing process and skin tissue regeneration with significant wound contraction, faster re-epithilisation, intense disposition of collagen bundles with a remarkable content of active fibroblasts. The effective wound healing properties of the formulation may also be attributed to the synergistic effect of the fatty acids, present in the oils. However, further studies evaluating the influence of individual oils/ components on maturation and proliferation of cellular components would provide insights into mechanism of accelerated wound healing.

\section{Conflict of interest}

The authors declare no conflict of interest.

\section{Acknowledgements}

The authors would like to thank Principal, Dr. D. Y. Patil Institute of Pharmaceutical Sciences and Research, Pimpri, Pune, India for providing necessary infrastructural facilities to carry out the work.

\section{References}

1. Sezer AD, Cevher E (2011) Biopolymers as Wound Healing materials Challenges and New Strategies. Biomaterials Applications for Nanomedicine 383-414.

2. Ahmed S, Ikram S (2016) Chitosan Based Scaffolds and their Applications in Wound Healing. Achievements in the Life Sciences 10: 27-37.

3. Aziz MA1, Cabral JD, Brooks HJ, Moratti SC, Hanton LR (2012) Antimicrobial properties of a chitosan dextran-based hydrogel for surgical use. Antimicrob Agents Chemother 56: 280-287. [Crossref]

4. Hurler J, Skalko-Basnet N (2012) Potentials of Chitosan-Based Delivery Systems in Wound Therapy: Bioadhesion Study. J Funct Biomater 3: 37-48. [Crossref]

5. Saladino S, Leonardo ER, Salamone M (2014) Formulation of Different Chitosan Hydrogels for Cartilage Tissue Repair. Chemical Engg Trans 38: 505-510.

6. Dai T, Tanaka M, Huang Y, Hamblin M (2011) Chitosan preparations for wounds and burns: antimicrobial and wound-healing effects. Expert Rev Anti Infect Ther. 9: 857-879. [Crossref]

7. Vyas LK, Tapar KK, Nema RK, Parashar AK (2013) Development and characterization of topical liposomal gel formulation for anti-cellulite activity. Int. J. Pharm. Pharm Sci. 5: 512-516.

8. Helal DA, El-Rheman DA, Abdel-Halim SA (2012) Formulation and evaluation of fluconazole topical gel. Int. J. Pharm. Pharm Sci. 4: 176-183.

9. Ishihara M, Nakanishi K, Ono K, Sato M, Kikuchi M, Saito Y (2002) Photo crosslinkable chitosan as a dressing for wound occlusion and accelerator in healing process. Biomaterials 23: 833-840. [Crossref]

10. Ruthig DJ, Meckling-Gill KA (1999) Both (n-3) and (n-6) fatty acids stimulate wound healing in the rat intestinal epithelial cell line, IEC-6. J Nutr 129: 1791-1798. [Crossref]

11. Pereira LM, Hatanaka E, Martins EF, Oliveira F, Liberti EA, et al. (2008) Effect of oleic and linoleic acids on the inflammatory phase of wound healing in rats. Cell Biochem Funct 26: 197-204. [Crossref] 
12. Edwards JV, Howley P, Davis R, Mashchak A, Goheen SC (2007) Protease inhibition by oleic acid transfer from chronic wound dressings to albumin. Int J Pharm 340: 4251. [Crossref]

13. Alexander JW, Supp DM1 (2014) Role of Arginine and Omega-3 Fatty Acids in Wound Healing and Infection. Adv Wound Care (New Rochelle) 3: 682-690. [Crossref]

14. Li HL, Chen LP, Hu YH, Qin Y, Liang G, et al. (2012) Crocodile oil enhances cutaneous burn wound healing and reduces scar formation in rats. Acad Emerg Med 19: 265-273. [Crossref]

15. Valacchi G, Lim Y, Belmonte G, Miracco C, Zanardi I, et al. (2011) Ozonated sesame oil enhances cutaneous wound healing in SKH1 mice. Wound Repair Regen 19: 107115. [Crossref]

16. Attarzadeh Y, Asilian A, Shahmoradi Z, Adibi N (2013) Comparing the efficacy of Emu oil with clotrimazole and hydrocortisone in the treatment of seborrheic dermatitis: A clinical trial. J Res Med Sci 18: 477-481. [Crossref]

17. Nickavar B, Mojab F, Javidnia K, Amoli MA (2003) Chemical composition of the fixed and volatile oils of Nigella sativa L. from Iran. Z Naturforsch C 58: 629-631. [Crossref]

18. Sultan MT, Butt MS, Anjum FM, Jamil A, Akhtar S (2009) Nutritional profile of indigenous cultivar of black cumin seeds and antioxidant potential of its fixed and essential oil. Pak J Bot. 41: 1321-1330.

19. Parakh PM (2010) Nigella sativa Linn- A comprehensive review. Indian J Nat Prod Resour. 1: 409-429.

20. USDA Foreign Agricultural Services, Global Agricultural Information Network (GAIN) report no:IN5124, Poultry and Poultry Products Annual, 2015.

21. Feddern V, Souza-Soares LA, Xu X (2013) Chicken skin fat as raw-material for modifying lipids to high value diacylglycerol rich in PUFA. III SIGER.

22. Oomah B (2001) Flaxseed as a functional food source. Journal of the Science of Food and Agriculture 81: 889-894.

23. Clark WF, Parbtani A, Huff MW, Spanner E, de Salis H, et al. (1995) Flaxseed: a potential treatment for lupus nephritis. Kidney Int 48: 475-480. [Crossref]

24. Cunnane SC, Ganguli S, Menard C, Liede AC, Hamadeh MJ, et al. (1993) High alphalinolenic acid flaxseed (Linum usitatissimum): some nutritional properties in humans. Br J Nutr 69: 443-453. [Crossref]

25. Thompson LU, Seidl MM, Rickard SE, Orcheson LJ, Fong HH (1996) Antitumorigenic effect of a mammalian lignan precursor from flaxseed. Nutr Cancer 26: 159-165. [Crossref]

26. Carvalho M, Mendonça M, Pinho D, Resck I, Suarez P (2012) Chromatographic analyses of fatty acid methyl esters by HPLC-UV and GC-FID. Journal of the Brazilian Chemical Society 23: 763-769.

27. Marinach C, Papillon M, Pepe C (2004) Identification of binding media in works of art by gas chromatography-mass spectrometry. Journal of Cultural Heritage 5: 231-240.

28. Tsakalof AK, Bairachtari KA, Chryssoulakis ID (2006) Pitfalls in drying oils identification in art objects by gas chromatography. J Sep Sci 29: 1642-1646. [Crossref]
29. Cappitelli F, Learner T, Chiantore O (2002) An initial assessment of thermally assisted hydrolysis and methylation-gas chromatography/mass spectrometry for the identification of oils from dried paint films. Journal of Analytical and Applied Pyrolysis 63: 339-348.

30. Food Safety and Standard Authority of India (2012) Lab manual of method and analysis of food.

31. Nebel AB, Bertram HC, Mortensen G, Hermansen K, Dalsgaard TK (2013) Novel method for quanti?cation of individual free fatty acids in milk using an in-solution derivatisation approach and gas chromatography-mass spectrometry. Int Dairy J 32: 199-203.

32. Carvalho M, Mendonça M, Pinho D, Resck I, Suarez P (2012) Chromatographic analyses of fatty acid methyl esters by HPLC-UV and GC-FID. Journal of the Brazilian Chemical Society 23: 763-769.

33. Cappitelli F, Learner T, Chiantore O (2002) An initial assessment of thermally assisted hydrolysis and methylation-gas chromatography/mass spectrometry for the identification of oils from dried paint films. Journal of Analytical and Applied Pyrolysis 63: 339-348.

34. Chattopadhyay DP, Inamdar MS (2010) Aqueous Behaviour of Chitosan. International Journal of Polymer Science 1-7.

35. Shinde PV, Shirolkar SV (2013) Formulation and Evaluation of Transdermal Patches of Metoclopramide Hydrochloride. AJPTI 1: 1-11.

36. Khan AW, Kotta S, Ansari SH, Sharma RK, Kumar A, et al. (2013) Formulation development, optimization and evaluation of aloe vera gel for wound healing. Pharmacogn Mag. 9: S6-10. [Crossref]

37. Guidelines for stability testing of drug product and substances Q1A (2014) International Conference of Harmonization for Technical Requirement.

38. Bairy KL, Somayaji SN, Rao CM (1997) An experimental model to produce partial thickness burn wound. Indian J Exp Biol 35: 70-72. [Crossref]

39. Kiran K, Asad M (2008) Wound healing activity of Sesamum indicum L seed and oil in rats. Indian J Exp Biol 46: 777-782. [Crossref]

40. Mitsunaga Junior JK, Gragnani A, Ramos ML, Ferreira LM (2012) Rat an experimental model for burns: a systematic review. Acta Cir Bras 27: 417-423. [Crossref]

41. Venkatesh MP, Purohit KL, Pramod Kumar TM. (2011) Development and evaluation of chitosan based thermosensitive in situ gels of pilocarpine. Int. J. Pharm. Pharm Sci 5: 164-169.

42. Kaur LP, Guleri TK (2013) Topical Gel: A Recent Approach for Novel Drug delivery Asian J. Biomed. Pharm. Sci 3: 1-5.

43. Ribeiro MP, Espiga A, Silva D, Baptista P, Henriques J, et al. (2009) Developmen of a new chitosan hydrogel for wound dressing. Wound Repair Regen 17: 817-824. [Crossref]

Copyright: (C2017 Thomas AB. This is an open-access article distributed under the terms of the Creative Commons Attribution License, which permits unrestricted use, distribution, and reproduction in any medium, provided the original author and source are credited. 